\title{
UNUSUAL BREAST TUMOR IN A PATIENT WITH MCCUNE ALBRIGHT SYNDROME: A CASE REPORT AND REVIEW OF THE LITERATURE
}

\author{
MARQUES P. ${ }^{* *}$, DOMINGUES R. ${ }^{2}$, PEREIRA J.S. ${ }^{1}$, VIEIRA M.S. ${ }^{1}$ AND PEREIRA C. ${ }^{1}$ \\ ${ }^{1}$ Endocrinology Department, Instituto Português de Oncologia de Lisboa, Francisco Gentil, Lisbon, Portugal. \\ 2Investigation Unit of Molecular Pathobiology, Instituto Português de Oncologia de Lisboa, Francisco Gentil, Lisbon, Portugal. \\ ${ }^{*}$ Corresponding Author: Email- pedro.miguel.sousa.marques@gmail.com
}

Received: February 13, 2014; Accepted: March 03, 2014

\begin{abstract}
Introduction: McCune Albright syndrome (MAS) is a rare disorder classically defined by the triad polyostotic fibrous dysplasia (FD), café-aulait pigmentation of the skin and precocious puberty (PP). Other endocrinopathies can be associated with MAS and nonendocrine tissues such as breast may be involved.

Case report: A 56-year-old woman was referred to our institution 20 years ago to treat a fast-growing infiltrative and ulcerative breast lesion, suspected as malignant. It was prompt operated and the $7 \mathrm{~cm}$-tumor was classified as a bening "breast tubular adenoma". From the anamnesis it was evident café-au-lait spots (present soon after birth) and multiple osteoarticular manifestations from the age of 13: pain and functional impotency of the left limb, past femoral fracture, kyphoscoliosis and facial asymmetry. The patient had also episodes of tachydysrhythmias. Laboratorial tests revealed hypophosphatemia, hyperphosphaturia, elevation of serum bone markers and primary hyperthyroidism. The imaging studies showed multiple FD areas and several bone deformities. The most frequent GNAS somatic mutation was not detected in four different types of tissue studied. The patient was managed with bisphosphonates, calcitriol and oral phosphate, with significant improvement. The hyperthyroidism was treated with radioiodine.

Discussion: We reported a MAS case with multiple endocrine and non-endocrine disease manifestations. The osseous disease is commonly the most prominent feature. Our patient had a unique fast-growing and infiltrative breast benign neoplasia, emphasizing the possible association of breast disorders in this setting. Genetic testing, not routinely available, may contribute little to the diagnosis and to the patient management.
\end{abstract}

Keywords- McCune Albright syndrome; fibrous dysplasia; breast

Running Title- Unusual breast tumor and McCune Albright syndrome

Citation: Marques P., et al. (2014) Unusual Breast Tumor in a Patient with Mccune Albright Syndrome: A Case Report and Review of the Literature. Medical Case Reports, ISSN: 0976-8726 \& E-ISSN: 0976-8734, Volume 5, Issue 1, pp.-055-059.

Copyright: Copyright@2014 Marques P., et al. This is an open-access article distributed under the terms of the Creative Commons Attribution License, which permits unrestricted use, distribution and reproduction in any medium, provided the original author and source are credited.

\section{Introduction}

McCune Albright syndrome (MAS) is a rare disorder (the estimated prevalence ranges between $1 / 100.000$ and $1 / 1.000 .000$ [1]) first reported in 1937 by McCune and shortly thereafter by Albright [2,3]. It is classically defined by the triad polyostotic fibrous dysplasia (FD), café-au-lait pigmentation of the skin and precocious puberty (PP). Later, it was recognized that other endocrinopathies can be associated with MAS like hyperthyroidism, growth hormone (GH) excess, Cushing syndrome, renal phosphate wasting and hyperparathyroidism, as well as nonendocrine organs disorders $[4,5]$. Those can occur alone or in combination and encompass a wide range of severity [6].

Activating mutations in the guanine-nucleotide binding protein (Gprotein) a-subunit (Gsa) that stimulates adenylate cyclase have been confirmed as the molecular cause of MAS [1-4]. These mutations are almost always a substitution of the residue arginine at position 201 by histidine or cysteine. The variable involvement of endocrine glands, the sporadic occurrence of this syndrome and the characteristic pattern of bone and skin lesions, which follows lines of embryologic development, are all in accordance with the mosaic distribution of abnormal cells due to the post-zygotic occurrence of the GNAS mutation [7]. Since these activating mutations occur in a mosaic distribution, a method that can detect even a low number of mutant alleles is required. Thus, several PCR based methods for mutational analyses have been reported [8-11].

As mentioned, nonendocrine systems such as liver, pancreas, heart or breast may be involved. Although less commonly, it is important to identify these disorders, because some may compromise the prognosis of these patients. Breast cancer has been described in MAS patients $[12,13]$ and must be excluded when a breast lesion is detected. We report a surprising benign breast tumor, thought as malignant from its behavior, in a MAS patient with multiple endocrine and nonendocrine manifestations. 


\section{Case Report}

We present a 56-year-old caucasian woman, referred to our institution 20 years ago because of a suspicious breast lesion. The sudden onset within 2 weeks and the fast and infiltrative growth rose concerning of this lesion as malignant. The breast lesion was localized in the upper and lower quadrants of the right breast, involving the nipple and prolonging to the axillary area, associated with an intense pain and inflammatory signs [Fig-1a]. Surgery was prompt performed and the histopathological examination revealed a "7-cm multinodular tumor, with papillary, tubular and cystic areas. Some stromal myoepithelial cells and extense solid groups of apocrine cells were present, but no mitoses or necrotic areas were visualized". This lesion was classified as a "breast tubular adenoma" by the pathologist.

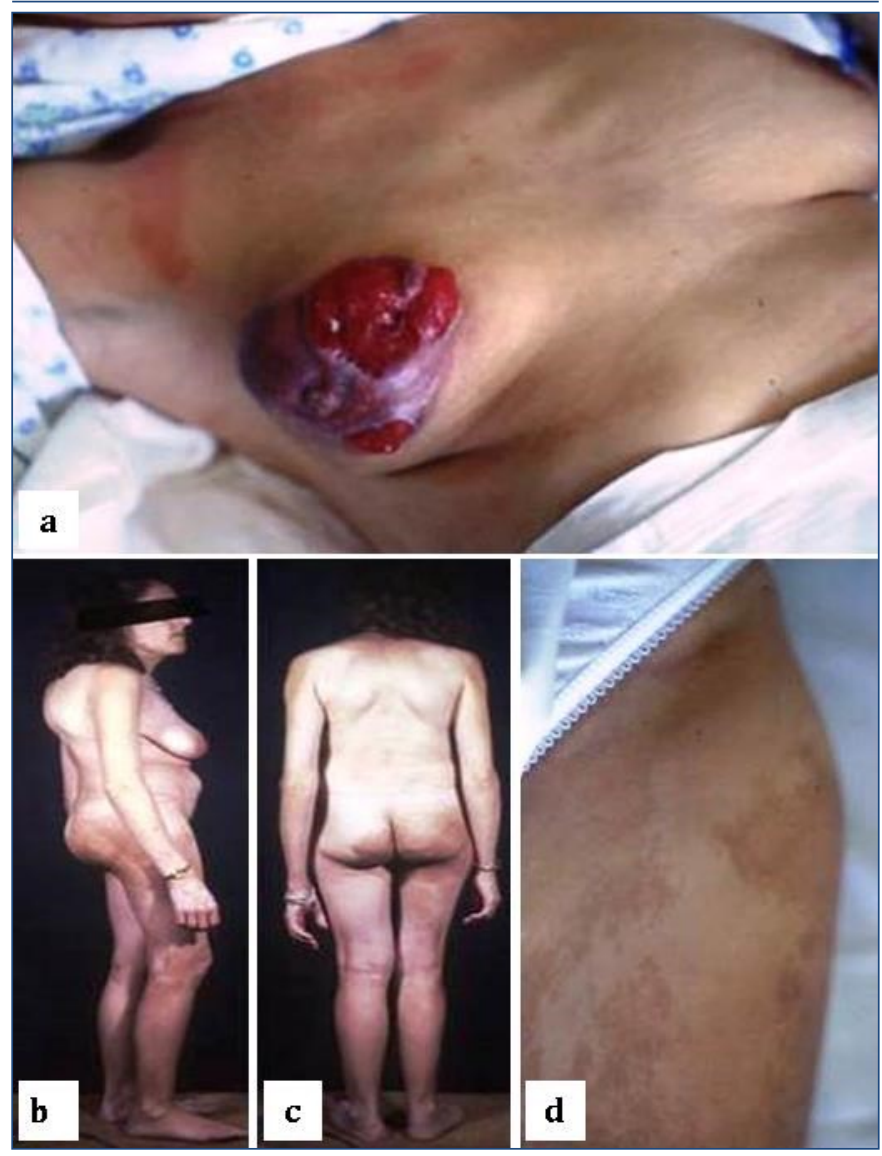

Fig. 1- Clinical features of the patient: (a) breast lesion localized in the upper and lower quadrants of the right breast; (b) lateral view of the patient where is evident the kyphoscoliosis; (c) café-au-lait spots in the left leg; (d) café-au-lait spots in buttock area (no respect of midline).

From the anamnesis it was noticeable pain and functional impotency of the left inferior limb at 13 years-old, sporadic facial pain and a femoral fracture by the age of 33 (bone biopsy documented FD). Concomitantly, facial asymmetry and kyphoscoliosis were known from the age of 18 and worsened progressively [Fig-1b]. There was no evidence of PP (menarche at age 13 and thelarche and pubarche at age 12). On examination it was seen large café-au-lait spots (present soon after birth) [Fig-1c] and [Fig-1d]. The patient had also episodes of tachydysrhythmias (later confirmed as a result of hyperthyroidism). No other past diseases or relevant family history was recognized. On a clinical basis, diagnosis of MAS was established.
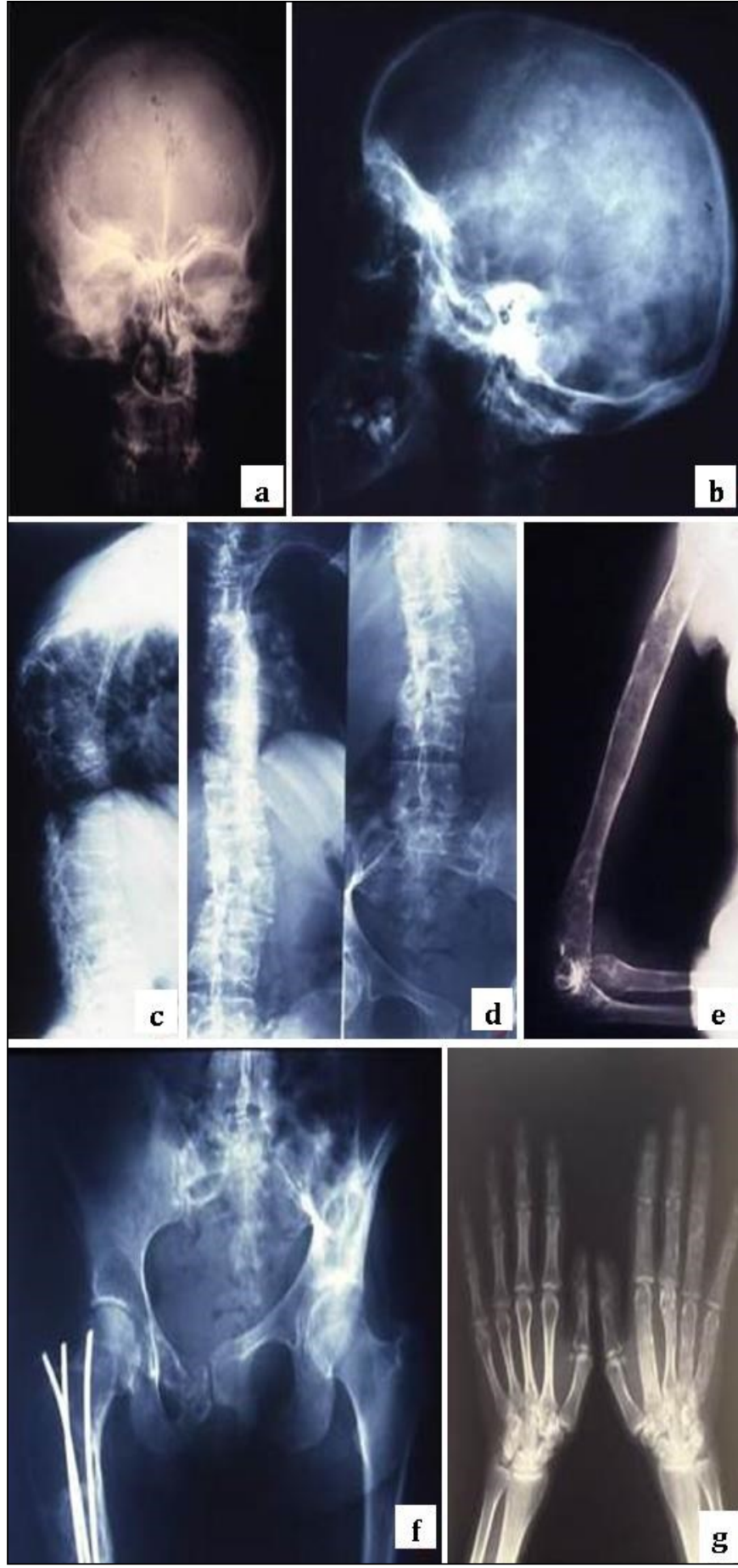

Fig. 2- Skeletal radiographs of the patient: (a \& b) skull "ground glass" lesions; (c \& d) kyphoscoliosis; (e) ground grass and cystic lesions, with thinning of cortical bone of left arm; (f) pelvic bones and right femur (post-operatory status; "shepherd's crook" deformity is visible); (g) FD lesions affecting the right hand bones.

Biochemically, blood count, coagulation, creatinine, sodium, potassium, calcium, D vitamin and PTH were within normal range. Renal phosphate wasting was identified by hypophosphatemia $(1.7 \mathrm{mg} / \mathrm{dL}$ (normal range: 2.3-4.7)) and hyperphosphaturia (1600 mg/24h (normal range: 400-1300)). Elevated bone markers confirmed high turnover (increased alkaline phosphatase(ALP)=596 IU/L (normal reference: 44-150), 85\% correspondent to bone fraction (normal < $30 \%)$ ). The patient was treated with bisphosphonates, calcitriol and 
oral phosphate, referring significant improvement. Currently, the bone disease is clinically asymptomatic. The patient had also a persistent cholestatic liver pattern (high $\gamma \mathrm{GT}$, ranging from 400 500IU/L (normal range:12-64)). At 44 years-old the patient underwent laparoscopic cholecystectomy due to biliary lithiasis.

Hormonal analysis detected primary hyperthyroidism $(\mathrm{TSH}<0.02 \mathrm{uUl} / \mathrm{mL}$ (0.34-5.6); free-T4 = 2.25ng/dL (0.61-1.12); FT3 $=4.1 \mathrm{pg} / \mathrm{mL}(2.5-3.9) ;$ TSH-receptor antibody and anti-thyroid peroxidase antibody were negative). It was excluded excess of $\mathrm{GH}$, prolactin or cortisol. Thyroid scintigraphy was performed showing diffuse hyperfunctioning gland. Thyroid ultrasound revealed multinodular goiter, two of them with a benign cytology. The hyperthyroidism was successfully treated with radioiodine.

The imaging studies showed a remarkable bone disease. Radio graphically, it was visible multiple FD areas, with heterogeneous bone texture including "ground glass" lesions, several cystic and lucent spaces [Fig-2a], [Fig-2b], [Fig-2e], [Fig-2g]. Kyphoscoliosis [Fig-2C] and [Fig-2d] and several bone deformities [Fig-2f] were also visualized. Bone scintigraphy staged the FD bone involvement [Fig3]. CT scans and the spine MRI showed FD bone lesions involving skull bones and the vertebral column [Fig-4]. Cardiovascular evaluation showed complete left bundle branch block and dissinergic movement of interventricular septum.

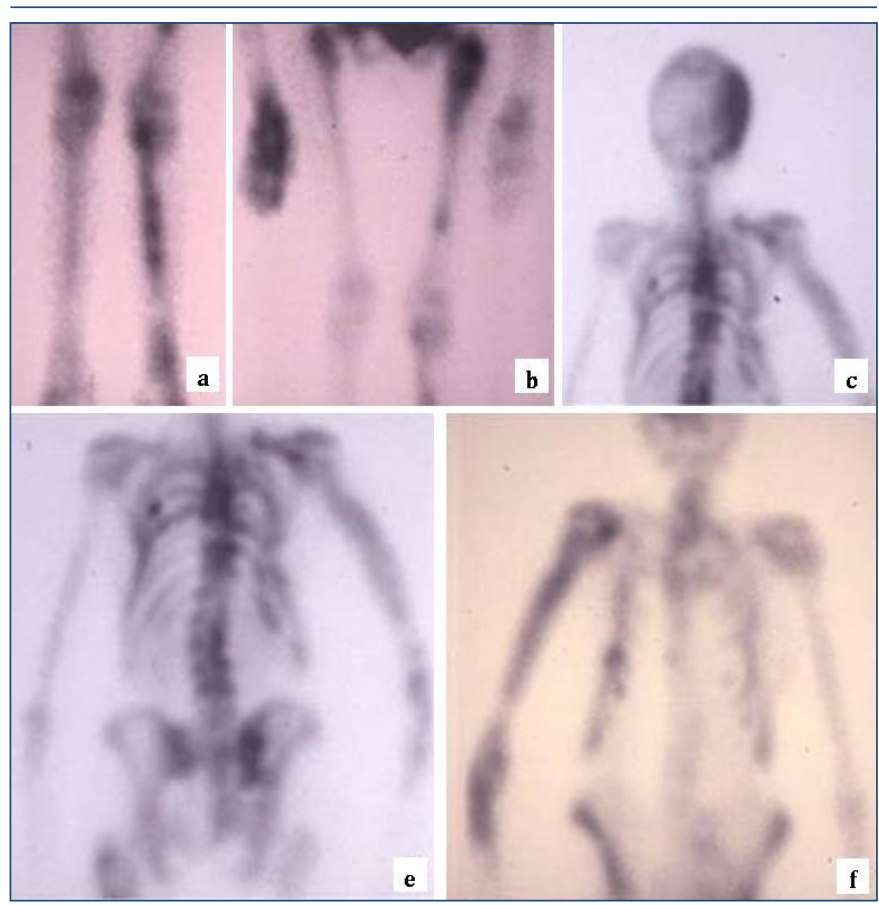

Fig. 3- Bone scintigraphy staging FD disease, with the tracer accumulation noticed in: (a) inferior limbs; (b) pelvic bones, femur heads and right hand; c) right fronto-parietal skull bones (posterior image); (c, d \& e) ribs and spine; (e) right arm.

Four different tissue samples from our case were available for genetic testing. Thus, DNA was extracted from peripheral blood leukocytes, epithelial cells from buccal swab, paraffin-embedded breast adenoma and fresh skin biopsy (café-au-lait lesion) using standard methods. In order to detect the Arg201 GNAS mutation we chose the method based on the use of a restriction endonuclease digestion with nested PCR to selectively digest the wild-type allele [9]. The principle is based on the use of a modified primer to obtain a PCR product from normal DNA that can be digested by a restriction enzyme (Eagl), whereas the PCR product obtained from mutated DNA is resistant to this enzyme. PCR amplification to introduce a site-directed mutation was performed first (sense primer: TTTTGTT TCAGGACCTGCTTCGCGGC; antisense primer: AAGCGTTCTTA CGAAC AGCCAAGC). After the site directed mutagenesis step, the $P C R$ product was treated with Eagl (New England Biolabs, Beverly, MA, USA) prior to further amplification. Digestion was carried out in a $10 \mathrm{ml}$ reaction composed of $1 \mathrm{ml}$ NEB3 10x buffer, $5 \mathrm{ml}$ PCR product, $2 \mathrm{ml}$ endonuclease $(10 \mathrm{U} / \mathrm{ml})$, and $2 \mathrm{ml}$ water at $37^{\circ} \mathrm{C}$ overnight. Successive PCR and enzyme digestion steps result in an enrichment of the mutated allele. The sense and antisense primers were those described by Candeliere [9] (second step antisense primer: ACAGCCAAGCCCACAGCATCCTAG; third antisense primer: GGTTATTCCAGAGGGACTGGGGTGAA). Two successive steps of PCR and digestion were used in this study to limit the risk of contamination due to the nested PCR. After purification, the final PCR products were sequenced with the internal antisense primer. No somatic mutation was detected in the four different types of tissue studied.
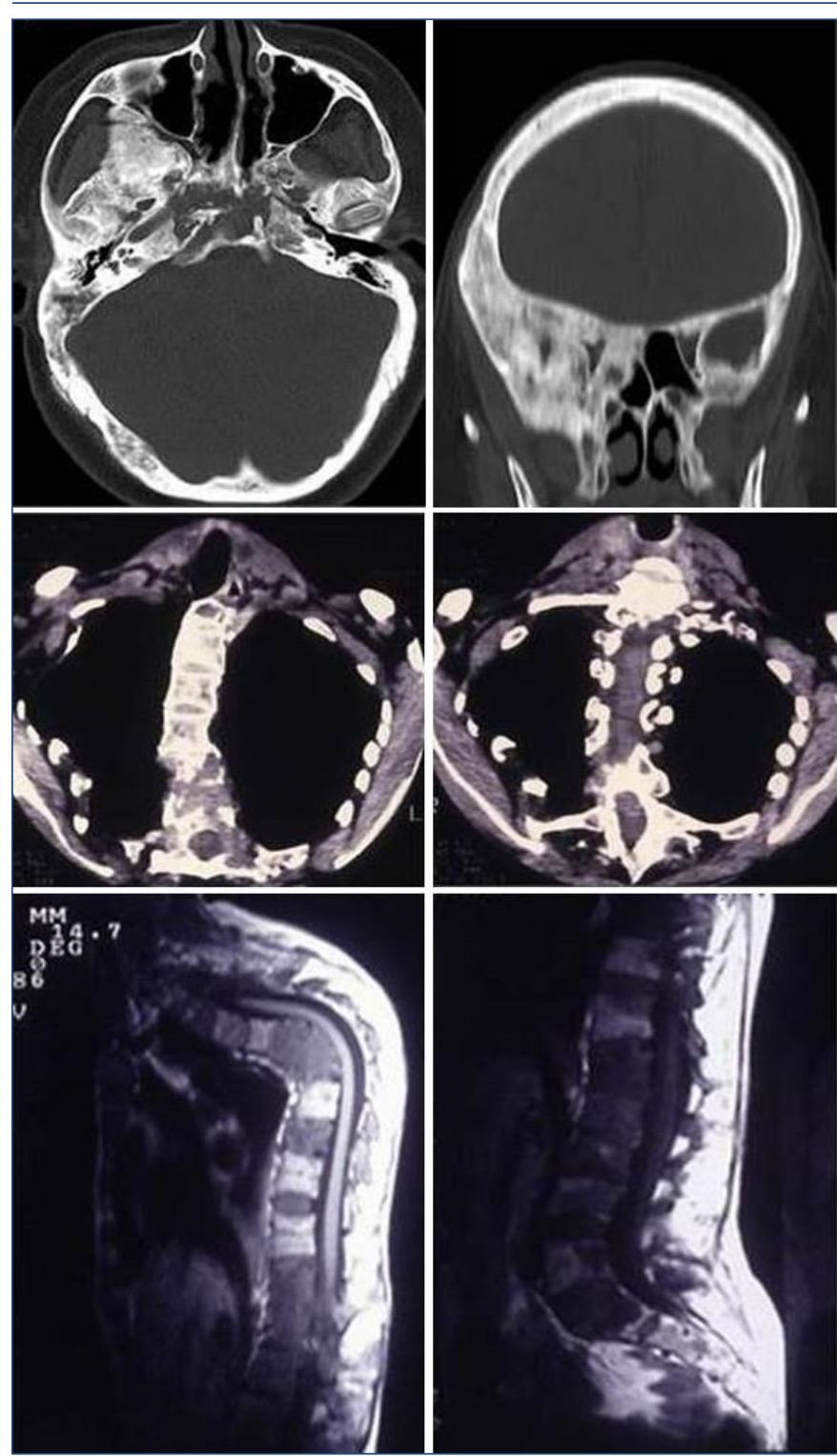

Fig. 4- CT scan and spine MRI images of the patient showing remarkable polyostotic FD lesions 


\section{Discussion}

FD accompanied by extraskeletal manifestations that can include any combination of skin café-au-lait spots, hyperfunctioning endocrinopathies, as well as less common systemical findings is known as MAS. The lack of vertical transmission of disease, the broad spectrum of involved tissues and the unpredictable combination of features is explained by the mosaic distribution of abnormal cells. The hyperpigmentation distribution following "Blaschko lines" (dorso -ventral outgrowths of separate populations during embryogenesis) supports the mosaicism theory, as well. MAS is not heritable, strengthening the argument that the mutation is lethal to the zygote $[7,14]$. The moment in development at which it occurs and to where its progeny migrate, determines what tissues will be affected and explains the variety in the clinical manifestation [15].

FD is a fibroosseous skeletal disorder with a broad spectrum of severity and corresponds to the most frequent finding in MAS. Initially, it was identified as distinct entity in association with skin spots and hyperfunctioning endocrinopathies by Donovan McCune and Fuller Albright $[2,3]$. Lichtenstein and Jaffe were the first ones describing the spectrum of clinical, radiographic and histological findings of FD [16,17]. In general, FD exists in 3 forms: monostotic $(70 \%)$, polyostotic (27\%) and polyostotic in MAS context (3\%) [18]. FD lesions are typically found in the long bones of extremities, ribs and craniofacial bones and rarely in hands, feet or spine. These lesions may be asymptomatic but often lead to bone deformity, pain, fractures or cranial nerve compression [4]. Craniofacial and appendicular FD lesions tend to slow or stop their progression after skeletal maturation (except in cases with $\mathrm{GH}$ excess) [19]. The fracture incidence reaches the peak between 6 and 10 years of age and declines thereafter [20].

FD lesions are composed mainly of fibrous tissue that originates in the medullary cavity and expands concentrically outward into the surrounding cortical bone through osteoclasts activity. Most of the cells are immature mesenchymal cells expressing ALP and other osteoblast-specific-proteins. Elevated cAMP may stimulate the proliferation and inhibit the differentiation of osteogenic precursors leading to FD $[4,19]$. Malignant or sarcomatous transformation of FD is a rare complication (1\% or less) [19]. Some endocrine dysfunctions concomitant in MAS may negatively impact in FD lesions: PP can lead to extremely short stature with bone bowing; $\mathrm{GH}$ excess can stimulate bone and FD lesions growth; hyperparathyroidism can increase the bone turnover; renal phosphate wasting and hypophosphatemia impair the normal bone mineralization [19-21]. Radiographs, bone scans, CT scan and MRI are useful imaging exams for FD [22]. The only medications that have shown any efficacy in treating FD were the bisphosponates [19].

Café-au-lait spots comprise another of the major hallmarks and are typically the first manifestation of MAS, usually appearing either at or shortly after birth, unilaterally and not crossing the midline $[5,23]$. These spots result of $g s p$-bearing melanocytes in which the mutation brings CAMP-mediated tyrosinase gene activation and melanin production [5].

The third facet of MAS is the endocrinopathies, from which the PP is predominant, especially in girls. The first sign of sexual precocity in females is premature menses, sometimes in the first months of life, accompanied or not by development of breast tissue or pubic hair. Usually females undergo normal development during adolescence and have normal reproduction function in adult life $[1,4]$. PP is biochemically defined by elevated estradiol and suppressed gon- adotropins, before 8 years old [24].

Thyroid disease is the second most common endocrinopathy in MAS. The mutation of the Gsa membrane-associated protein gene, that mediates the TSH-induced adenyl cyclase, leads to cAMP overproduction, hormonal secretion and growth of thyrocytes [25]. Additionally, this mutations result in increased thyroxine to triiodothyronine (T3) conversion, which responds for the T3-dominant biochemical phenotype that MAS hyperthyroidism normally have [26]. Hyperthyroidism with or without goiter in MAS is common and should be treat definitively with radioiodine or surgery. Some authors suggested radioiodine as the appropriate treatment because hyperthyroidism is very likely to recur after withdrawal of antithyroid medication and the surgery in these patients is often limited due to the skeletal disease [25].

Hyperphosphaturic hypophosphatemia is present in almost $50 \%$ of MAS patients. It has been postulated that hyperphosphaturia is due to the overproduction of a phosphaturic factor (FGF-23) from FD tissue [21]. Hypophosphatemia is only seen in patients with significant skeletal burden of FD and unlike many extraskeletal manifestations, renal phosphate wasting can spontaneously resolve [5]. Treatment may involve the use of phosphate and active vitamin D [5].

Our patient had all the features so far described, except of PP. Other endocrine abnormalities, not present in our patient, can be seen in MAS patients such as Cushing syndrome [27], excess of GH [28], hyperparathyroidism and prolactinomas [4]. Treatment is similar to the standard care for patients with these individual diseases [18].

Although the abnormalities in MAS are generally restricted to bone, skin and endocrine organs, nonendocrine organs may be affected, including liver, breast, heart, thymus, spleen, brain and gastrointestinal tract [5].

Hepatobiliary dysfunction is included in the nonendocrine abnormalities, and although it appears to be a rare manifestation, severe neonatal jaundice, persistent elevated serum liver enzymes and liver cirrhosis have been describe alone or in combination. The mentioned activating mutation has been isolated in liver tissue of affected patients and is thought to play a role in the pathogenesis of cholestasis, possibly by interfering with normal biliary excretion by the liver cell. The defect may lie at hepatocyte and/or biliary canalicular membrane level [29]. Our patient had persistently a cholestatic pattern in blood tests and underwent cholecystectomy due to biliary lithiasis.

There are several cardiac abnormalities that have been reported in MAS including sudden death, tachycardia, heart failure and aortic roof dilatation [5]. None of them were seen in our patient, but a complete left bundle branch block was noticed conditioning a dissinergic movement of interventricular septum.

The most remarkable feature of our patient was the sudden-onset of a fast-growing and infiltrative benign breast tumor, behavioring as malignant, at the age of 36 in a patient with no familial history of breast cancer. To our knowledge, it is not yet described in the literature a benign breast tumor with this clinical presentation in MAS. However, two cases of breast cancer are reported in MAS patients $[12,13]$. In both, the women had PP and since prolonged estrogen exposure which constitute an isolated risk factor for breast cancer. The authors highlight the need for evaluation of breast tissue in MAS patients. Other oncological diseases has been identified in MAS patients like malignant transformation of FD, testicular or thyroid cancer $[1,5,30]$. 
Other nonendocrine disorders can be present in MAS patients, such as platelet dysfunction, gastrointestinal reflux, gastrointestinal polyps, idiopathic pancreatitis and neuropsychiatric disorders [5]. None were found in our patient.

Genetic testing is possible, but not routinely available. In most cases, genetic testing contributes little to the diagnosis or to the patient management (there is no genotype/phenotype correlation). Because of the somatic mosaic nature of the disease, a negative result from available (but unaffected) tissues does not exclude the presence of the mutation [31]. For example, the involvement of blood in the disease process is indirect and the presence of cells bearing the mutation can be extremely low. In a meta-analysis study [32] GNAS mutations were detected in $71.9 \%$ of overall cases. In our case, we used a previously described, highly sensitive PCR based technique that allows the selective enrichment of mutated DNA [9], but no somatic mutation was detected in the four different types of tissue studied. Nevertheless, nested PCR remains the most sensitive technique, especially for the incomplete and atypical forms of MAS [33]. Despite a highly sensitive detection method, some samples may remain negative. Mutated cells may be confined to only specific loci in the affected tissue, and some breast or skin samples, for example, will be negative if the biopsy has missed these loci [32,33].

We report a MAS case with multiple endocrine and nonendocrine manifestations. The osseous disease is commonly the most prominent feature. Our patient had a unique fast-growing benign breast neoplasia, emphasizing the possible association of breast disease with MAS and the importance of ruling out breast disorders in this setting. Genetic testing contributes little to the diagnosis and to the management because of the somatic mosaic nature of MAS.

Conflicts of Interest: The authors have nothing to disclose.

\section{References}

[1] Dumitrescu C.E. and Collins M.T. (2008) Orphanet Journal of Rare Diseases, 3(5), 1-12.

[2] McCune D.J. (1936) Am. J. Dis. Child., 52, 743-744.

[3] Albright F., Butler A.M., Hampton A.O. and Smith P. (1937) N. Engl. J. Med., 216, 727-746.

[4] Weinstein L.S., Yu S., Warner D.R. And Liu J. (2001) Endocr., 22(5), 675-705.

[5] Collins M.T., Singer F.R. And Eugster E. (2012) Orphanet Journal of Rare Diseases, 7(1), S4.

[6] Lumbroso S., Paris F. and Sultan C. (2004) J. Clin. Endocrinol. Metab., 89, 2107-2113.

[7] Happle R. (1986) Clin. Genet., 29, 321-324.

[8] Lietman S.A., Ding C. and Levine M.A. (2005) J. Bone Joint Surg. Am., 87, 2489-2494.

[9] Candeliere G.A., Roughley P.J. and Glorieux F.H. (1997) Bone, 21, 201-206.

[10]Bianco P., Riminucci M., Majolagbe A., Kuznetsov S.A., Collins M.T., Mankani M.H., Corsi A., Bone H.G., Wientroub S., Spiegel A.M., Fisher L.W. and Robey P.G. (2000) J. Bone Miner Res., $15,120-128$.

[11]Karadag A., Riminucci M., Bianco P., Cherman N., Kuznetsov S.A., Nguyen N., Collins M.T., Robey P.G. and Fisher L.W. (2004) Nucleic Acids Res., 32, e63.
[12]Tanabe Y., Nakahara S., Mitsuyama S., Ono M. and Toyoshima (1998) Breast Cancer, 5(2), 175-178.

[13]Huston T.L. and Simmons R.M. (2004) Breast J., 10(5), 440442.

[14]Rieger E., Kofler R., Borkenstein M., Schwingshandl J., Soyer H.P. and Kerl H. (1994) Br. J. Dermatol., 130, 215-220.

[15]Shenker A., Weinstein L.S., Moran A., Pescovitz O.H., Charest N.J., Boney C.M., Van Wyk J.J., Merino M.J., Feuillan P.P. and Spiegel A.M. (1993) J. Pediatr., 123, 509-518.

[16]Lichtenstein L. (1938) Arch. Surg., 36, 874-898.

[17]Lichtenstein L. and Jaffe H.L. (1942) Arch. Pathol., 33, 777-816.

[18]Rubio N.I., Nader S. and Brosnan P.G. (2006) Int. J. Endocrinol. Metab., 3, 167-175.

[19]Leet A.I. and Collins M.T. (2007) J. Child. Orthop., 1, 3-17.

[20]Leet A.I., Chebli C., Kushner H., Chen C.C., Kelly M.H., Brillante B.A., Robey P.G., Bianco P., Wientroub S. and Collins M.T. (2004) J. Bone Miner Res., 19, 571-577.

[21]Riminucci M., Collins M.T., Fedarko N.S., Cherman N., Corsi A., White K.E., Waguespack S., Gupta A., Hannon T., Econs M.J., Bianco P. and Robey P.G. (2003) J. Clin. Invest., 112, 683-692.

[22]Lisle D.A., Monsour P.A.J. and Maskiell C.D. (2008) J. Med. Imaging Radiat. Oncol., 52, 325-332.

[23]Ozawa T., Tasteishi C., Shirakawa M., Murakami E., Ishii M. and Harada T. (2011) Dermatol. Surg., 37, 263-266.

[24]Boussaid K., Meduri G., Maiza J.C., Gennero I., Escourrou G., Bros A., Leguevaque P., Bennet A. and Caron P. (2013) J. Clin. Endocrinol. Metab., 98(2), E314-E320.

[25]Mastorakos G., Mitsiades N.S., Doufas A.G. And Koutras D.A. (1997) Thyroid, 7(3), 433-439.

[26]Celi F.S., Coppotelli G., Chidakel A., Kelly M., Brillante B.A., Shawker T., Cherman N., Feuillan P.P. And Collins M.T. (2008) J. Clin. Endocrinol. Metab., 93(6), 2383-2389.

[27]Brown R.J., Kelly M.H. and Collins M.T. (2010) J. Clin. Endocrinol. Metab., 95(4), 1508-1515.

[28]Bhansali A., Sharma B.S., Sreenivasulu P., Singh P., Vashisth R.K. and Dash R.J. (2003) Endocr. J., 50, 793-799.

[29]Silva E.S., Lumbroso S., Medina M., Gillerot Y., Sultan C. and Sokal E.M. (2000) Hepatol., 32, 154-158.

[30]Collins M.T., Sarlis N.J., Merino M.J., Monroe J., Crawford S.F., Krakoff J.A., Guthrie L.C., Bonat S., Robey P.G. and Shenker A. (2003) J. Clin. Endocrinol. Metab., 88(9), 4413-4417.

[31]Weinstein L.S. (2007) J. Bone. Miner Res., 21, 120-124.

[32]Lee S.E., Lee E.H., Park H., Sung J.Y., Lee H.W., Kang S.Y., Seo S., Kim B.H., Lee H., Seo A.N., Ahn G. and Choi Y.L.. (2012) Hum Pathol, 43(8), 1234-1242.

[33]Kalfa N., Philibert P., Audran F., Ecochard A., Hannon T., Lumbroso S. and Sultan C. (2006) Eur. J. Endocrinol., 155(6), 839843. 